INTERNATIONAL JOURNAL OF RESEARCHES IN BIOSCIENCES, AGRICULTURE AND TECHNOLOGY (C) VISHWASHANTI MULTIPURPOSE SOCIETY (Global Peace Multipurpose Society) R. No. MH-659/13(N) www.vmsindia.org

\title{
RESPONSE OF DIFFERENT BANANA CULTIVARS TO IN VITRO PROPAGATION
}

\author{
M. C. Kale \\ Anand Niketan College, Anandwan, Warora, District Chandrapur, \\ Maharashtra, soham_kale59@rediffmail.com
}

\begin{abstract}
:
Banana is the most widely cultivate fruit crop in India. Development of a cultivar specific micropropagation protocol for production of in vitro virus free plantlets is essential. In the present investigation four cultivars of banana viz., Basrai, Grand naine, Ardhapuri and Srimanti were used for development of micropropagation protocol through shoot tip cultures. The response of Grand naine cultivar was maximum. Whole plant regeneration protocol was successfully developed for all four cultivars with a success rate of 92-97\%.
\end{abstract}

Keywords: Banana, Musa, Basrai, Grand Naine, Ardhapuri, Srimanti, micropropagation, shoot tip cultures.

\section{Introduction:}

In India, banana contributes to the $33 \%$ of the total food production and rank second in importance next to mango. The state of Maharashtra ranks second with respect to the land under cultivation but first in its production of banana with 65.70 MT/ha per annum (Indian Horticulture Database, 2013). The use of in vitro plantlets is one of the main improvements in cultivation of banana during the last decade. Banana is the most widely in vitro propagated plant with worldwide production of about 50 million plants per year. In addition to the advantages of using little space and providing continuous availability, the plants produced by in vitro micropropagation of shoot tips have a very high sanitary quality. If combined with appropriate agronomic practices, in vitro plants give high yield with reduced pesticide use. Banana tissue culture plantlets have several advantages. They have higher survival rates than suckers, reduced the cost of disease and pest control, show uniform and vigorous growth, and have shorter harvesting period. The present investigation therefore aims to study the response of different banana cultivars for micropropagation through in vitro shoot tip culture. This evaluation will help to develop a cultivar specific protocol for commercialization of in vitro developed plantlets.

\section{Material And Methods:}

\section{Shoot tip cultures}

Banana cultivars Basrai, Grand naine, Srimanti, and Ardhapuri were procured from nearby fields and multiplied in the research filed of Anand Niketan College, Anandwan. For in vitro multiplication shoot tips from young suckers from 10-45 $\mathrm{cm}$ height were used as explants. From the selected suckers shoot tips of 1-2 cm height containing the apical meristems were excised. The excised shoot tips were surface sterilized with $70 \%$ ethanol for one minute, $2 \%$ sodium hypochlorite solution for 10 minutes and subsequently washed three times with sterile distilled water after chemical sterilization. Subsequently the shoot tips were dissected and reduced to 1-3 $\mathrm{mm}$ height with a thin layer of corm tissue at the base. Such shoot tips were inoculated in establishment medium comprising of MS basal medium supplemented with $30 \mathrm{~g} / 1$ sucrose. The establishment medium also included antioxidants such as ascorbic acid $(50 \mathrm{mg} / 1)$ to reduce blackening and exudation of phenolic compounds from injured tissue into the medium. Benzyl amino purine in the range from $0.5-2 \mathrm{mg} / 1$ was used for selection of best establishment medium. All the cultures were incubated at optimal growth temperature of $26 \pm$ $2{ }^{\circ} \mathrm{C}$ and 16 hours photoperiod with the photosynthetic photon flux of about $60 \mu \mathrm{E} / \mathrm{m}^{2}$ $\mathrm{s}^{1}$. The shoot tips were kept in establishment medium for 4-6 weeks and were subcultured every 15 days.

\section{Multiplication of shoot tip cultures}

The formation of multiple shoots was induced in MS basal medium supplemented with relatively high concentration of cytokinin. In the present investigation MS medium containing 2, 4, 6 and $8 \mathrm{mg} / 1 \mathrm{BAP}$ and $0.5 \mathrm{mg} / 1$ kinetin was used. Induced multiple shoots were separated, trimmed and repeatedly subcultured at 4-6 weeks intervals.

\section{Regeneration of whole plants}

Whole plants were regenerated from the shoots after inoculation in root induction medium comprising of half strength MS medium containing 1-2 mg/1 IAA. Activated charcoal $(0.1 \%)$ was added to the rooting medium to enhance rooting.

\section{Result and Discussion:}

To initiate micro-propagation of banana cultivars, hardy mother plants that were able to 
tolerate high summer temperatures were selected. Suckers from such 10 month old mother plants were removed for experimentation. The response of suckers on establishment medium was investigated.

\section{Response of banana cultivars in establishment medium}

The response of sucker length on the establishment medium was investigated. Suckers of three different sizes were selected for the purpose $(10-20 \mathrm{~cm}, 21-35 \mathrm{~cm}, 36-45 \mathrm{~cm})$. Out of the sucker sizes selected, the best response was given by suckers of length 21-35 $\mathrm{cm}$, for all the cultivars tested. Similar observations regarding the proper age or size of sucker was reported by Okole and Schultz, 1996. With increase in sucker size the response for multiple shoot initiation decreased probably due to the reduction of meristematic zone and increase in the differentiated zone of the shoot apical meristem.

The response of different cultivars on establishment medium comprising of BAP and Kinetin was investigated. In general BAP favoured better establishment of shoot tips over kinetin. The present findings are in agreement with those of Miller and Murashige, 1976; Damascoa and Barba 1984. Amongst the different hormone combinations tried, the performance of Grand naine cultivar was the best with highest percentage of successful established cultures (98\%), the response of Ardhapuri was the least (92\%). The establishment percentage of Basrai and Srimanti were found to be 97 and $95 \%$ respectively (Table-1).

Different hormone combinations were tried for successful establishment of apical meristems. Response shown by different cultivars was found to vary considerably. The response of Basrai and Ardhapuri was maximum 97 and $92 \%$ respectively in $1.5 \mathrm{mg} / 1$ BAP, while the cultivar Grand naine responded more efficiently to $1 \mathrm{mg} / 1$ BAP (98\%). The cultivar Srimanti showed maximum response in $2 \mathrm{mg} / 1$ BAP (95\%). Similar results were reported by Banerjee et al., 1986; Bekheet and Saker, 1999; Oliveira de Almeida et al., 2000; Ali et al 2011. In general the overall response of the cultivar Grand naine was more superior over all other cultivars tested.

\section{Induction of multiple shoots in banana cultivars}

The established apical meristems were split vertically and the resulting halves were transferred aseptically on the shoot proliferation medium comprising of different combinations of
BAP and Kinetin. Four different concentrations of BAP were tested $(2,4,6,8 \mathrm{mg} / 1)$, keeping the concentration of kinetin constant to $0.5 \mathrm{mg} / 1$. Higher ratio of BAP to kinetin in general favoured higher proliferation rates. The response of banana cultivar Grand naine was maximum with around eight multiple shoots per meristem, while the response of Srimanti was the least with about six multiple shoots per meristem (Table-2). A positive correlation between increase in shoot multiplication and BAP concentration was also reported by Arinaitwe, 2000; Hirimburegama, 1996; Dhumale et al., 1997.

Different hormone combinations were tried and the response of Basrai and Grand naine was maximum to $6 \mathrm{mg} / 1 \mathrm{BAP}$ and 0.5 mg/1 Kinetin with 8.2 and 7.6 multiple shoots respectively. In the cultivars Ardhapuri and Srimanti 7.48 and 6.24 multiple shoots were induced in hormone combination $4 \mathrm{mg} / 1 \mathrm{BAP}$ and $0.5 \mathrm{mg} / 1$ kinetin (Table-2).

\section{Induction of roots in half strength MS medium}

The response of different banana cultivars for the induction of roots in all the concentrations of IAA was cultivar specific with respect to the days required for induction and success rate. A minimum of 14-20 days were required for root induction depending upon the cultivar. Earliest response to rooting in 14 days was shown by Grand naine, while the slowest response that is 20 days was observed in Srimanti. In all the cultivars maximum rooting was induced in $1.5 \mathrm{mg} / 1$ IAA. Maximum root were induced in this concentration in the cultivar Grand naine (7.50), while the least number of roots (4.25) were induced in the cultivar Srimanti (Table-3).

Grand naine proved to be superior in performance with success rate of $97 \%$ for root induction while the least response of $92 \%$ was given by Srimanti (Table-3). Cronauer and Krikorian (1984a), Bekheet and Saker (1999) and Rahman et al. (2002) also reported such rapid and profuse root induction and proliferation in excised shoots.

\section{Survival Percentage}

Well grown plantlets with a mean shoot height of $6 \mathrm{~cm}$ and root length $8 \mathrm{~cm}$ were removed from the culture tube or bottle, washed and transferred to sand, soil, cow dung mixture in a ratio of $1: 1: 1$. The plantlets were hardened in culture room under conditions of high humidity for fifteen days and then transferred to greenhouse. The survival percentage ranged 
between 75 to $82 \%$ depending upon the cultivar.

The Survival percentage of Grand naine was

maximum and that of Srimanti was the least.

Table 1. Response of banana cultivars in establishment medium (MS basal supplemented with benzyl amino purine):

\begin{tabular}{|c|c|c|c|c|c|}
\hline Cultivar & Length of sucker & $0.5 \mathrm{mg} / 1$ & $1 \mathrm{mg} / 1$ & $1.5 \mathrm{mg} / 1$ & $2.0 \mathrm{mg} / 1$ \\
\hline \multirow{3}{*}{ Basrai } & $10-20 \mathrm{~cm}$ & No response & $84 \%$ & $95 \%$ & $89 \%$ \\
\cline { 2 - 5 } & $21-35 \mathrm{~cm}$ & $38 \%$ & $65 \%$ & $97 \%$ & $91 \%$ \\
\cline { 2 - 5 } & $36-45 \mathrm{~cm}$ & $23 \%$ & $48 \%$ & $86 \%$ & $78 \%$ \\
\hline \multirow{3}{*}{ Grand naine } & $10-20 \mathrm{~cm}$ & $32 \%$ & $75 \%$ & $64 \%$ & $52 \%$ \\
\cline { 2 - 6 } & $21-35 \mathrm{~cm}$ & $46 \%$ & $98 \%$ & $79 \%$ & $65 \%$ \\
\cline { 2 - 6 } & $36-45 \mathrm{~cm}$ & $41 \%$ & $78 \%$ & $62 \%$ & $55 \%$ \\
\hline \multirow{3}{*}{ Srimanti } & $10-20 \mathrm{~cm}$ & $25 \%$ & $52 \%$ & $76 \%$ & $82 \%$ \\
\cline { 2 - 6 } & $21-35 \mathrm{~cm}$ & $38 \%$ & $57 \%$ & $79 \%$ & $95 \%$ \\
\cline { 2 - 6 } Ardhapuri & $36-45 \mathrm{~cm}$ & $35 \%$ & $65 \%$ & $83 \%$ & $90 \%$ \\
\cline { 2 - 6 } & $10-20 \mathrm{~cm}$ & $30 \%$ & $45 \%$ & $88 \%$ & $66 \%$ \\
\cline { 2 - 6 } & $21-35 \mathrm{~cm}$ & $51 \%$ & $76 \%$ & $92 \%$ & $88 \%$ \\
\hline \multirow{3}{*}{} & $36-45 \mathrm{~cm}$ & $29 \%$ & $38 \%$ & $75 \%$ & $74 \%$ \\
\hline
\end{tabular}

Table 2. Induction of multiple shoots in banana cultivars:

\begin{tabular}{|c|c|c|c|}
\hline Cultivars & BAP mg/1 & Kinetin $\mathrm{mg} / 1$ & No. of shoots \\
\hline \multirow{4}{*}{ Basrai } & 2.0 & 0.5 & 5.46 \\
\cline { 2 - 4 } & 4.0 & 0.5 & 7.25 \\
\cline { 2 - 4 } & 6.0 & 0.5 & 7.64 \\
\cline { 2 - 4 } & 8.0 & 0.5 & 5.30 \\
\hline \multirow{4}{*}{ Grand naine } & 2.0 & 0.5 & 6.40 \\
\cline { 2 - 4 } & 4.0 & 0.5 & 7.50 \\
\cline { 2 - 4 } & 6.0 & 0.5 & 8.20 \\
\cline { 2 - 4 } & 8.0 & 0.5 & 7.60 \\
\hline \multirow{4}{*}{ Srimanti } & 2.0 & 0.5 & 5.46 \\
\cline { 2 - 4 } & 4.0 & 0.5 & 6.24 \\
\cline { 2 - 4 } & 6.0 & 0.5 & 3.65 \\
\cline { 2 - 4 } & 8.0 & 0.5 & 2.04 \\
\hline \multirow{3}{*}{ Ardhapuri } & 2.0 & 0.5 & 3.25 \\
\cline { 2 - 4 } & 4.0 & 0.5 & 7.48 \\
\cline { 2 - 4 } & 6.0 & 0.5 & 4.36 \\
\cline { 2 - 4 } & 8.0 & 0.5 & 2.18 \\
\hline
\end{tabular}

Table 3. Induction of roots in banana cultivars on half strength MS medium:

\begin{tabular}{|c|c|c|c|c|}
\hline Cultivar & IAA mg/1 & No. of roots & Days to induction & Success \% \\
\hline \multirow{3}{*}{ Basrai } & 1.0 & 3.72 & 18 & 93 \\
\cline { 2 - 5 } & 1.5 & 4.78 & 17 & 95 \\
\cline { 2 - 5 } & 2.0 & 3.75 & 19 & 94 \\
\hline \multirow{3}{*}{ Grand naine } & 1.0 & 6.25 & 15 & 97 \\
\cline { 2 - 5 } & 1.5 & 7.50 & 14 & 96 \\
\cline { 2 - 5 } Srimanti & 2.0 & 5.45 & 17 & 95 \\
\hline & 1.0 & 3.74 & 22 & 89 \\
\cline { 2 - 5 } & 1.5 & 4.25 & 20 & 94 \\
\hline \multirow{3}{*}{ Ardhapuri } & 2.0 & 3.80 & 23 & 92 \\
\cline { 2 - 5 } & 1.0 & 3.68 & 24 & 83 \\
\cline { 2 - 5 } & 2.5 & 4.50 & 19 & 89 \\
\hline
\end{tabular}

\section{Conclusion:}

The application of somaclonal variation, tissue culture and micropropagation seems to be the best option available not only for quality improvement, but also for commercial exploitation of this crop that has great economic potential. Micropropagation of banana is currently being done to produce large population of clones that are disease free (Cote et al., 1990; Buah et al., 2000). However, the multiplications vary with genotype or races (Jambhale et al., 2001). Hence in the present investigation, attempts were made to develop a suitable micropropagation protocol that can be used for rapid multiplication of different banana cultivars. The results were highly promising and it can therefore, be concluded that a successful protocol can be developed for commercial exploitation of all the banana cultivars.

\section{References:}

Ali, A., Sajid A., Naveed, N. H., Majid, A., Saleem, A., Khan, U. A., Jafery, F. I. and Naz, S. (2011): Initiation, proliferation and development of micropropagation system for mass scale production of banana through 
meristem culture. African Journal of Biotechnology. Vol. 10(70): Pp. 15731-15738.

Arinaitwe, G., Rubaihayo, P. R., Magambo, M. J. S. (2000): Proliferation rate effects of cytokinins on banana (Musa spp.) cultivars. Scientia Hort. 86: Pp.13-21.

Banerjee, N., Vuylsteke, D., Langhe, E. (1986): Meristem tip culture of Musa: histomorphological studies of shoot bud proliferation. In Plant Tiss. Cult. and its Agricult. Application, edited by Withers, L. A., Alderson, P. G., Bufferworths, London, UK.

Bekheet S. A. and M. M. Saker (1999): Rapid mass propagation of Banana. Bull. NRC, Egypt. Vol. 24 (2): Pp. 221-232.

Buah, J. N., Kawamitsu, Y., Yonemori, S., Hayashi, M. and Murayama, S. (2000): Effects of various carbon sources and their combinations on in vitro growth and photosynthesis in banana (Musa spp.) plantlets. Plant Prod. Sci. Vol. 3: Pp. 392-397.

Indian Horticulture Database: Chaper 9 HORTICULTURE (2013) : Downloaded from nhb.gov.in/area-

pro/Indian\% 20Horticulture\% 202013.pdf on 09/04/2015.

Cote, F., Alvard, D., Domergue, R., Mastache, L. N. and Teisson, C. (1990): Micropropagation in vitro du bananier, Fruits. Vol. 45: Pp. 112118.

Cronauer, S. S., Krikorian, A. D. (1984a): Rapid multiplication of banana and plantains by in vitro shoot tip culture. Hort. Sci. Vol. 19(2): Pp. 234-235.

Dhumale, D., Kadu, A., Gholary, s. and Ingole, G. (1997): In vitro multiplication of banana var. 'Shrimanti' from the shoot tip explants. Annals of Plant Physiology. Vol. 11: Pp. 214-218.

Damasco, O. P. and Barba, R. C. (1984): Invitro culture of Saba (Musa Spp. cv. Saba BBB). Philippine Agriculturist. Vol. 67: Pp 351-358.

Hirimburegama, K. (1996): Biotechnology in Agriculture. Proc of 52nd Annual Sessions of SLAAS. Part II. Sri Lanka Association for the Advancement of Science, Colombo.

Jambhale, N., Patil, S., Jadhav, A., Pawar, S. and Waghmode, B. (2001): Effect of number of subcultures on in vitro multiplication of four banana clones. InfoMusa. Vol. 10: Pp.38-39.

Miller, L. R. and Murashige, T. (1976): Tissue culture propagation of tropical foliage plants. In vitro. Vol. 12: Pp. 797-813.

Okole, B. N. and Schultz, F. A. (1996): Microcross sections of Banana and plantains (Musa spp.): Morphogenesis and regeneration of callus and shoot buds. Plant Sci. Vol. 116: Pp. 185-195.

Oliveira de Almeida, C., Silva Souza, J. da, Souza Leal, M. de, Loyola Dantas, J.L. (2000): The banana crop in Brazil: Economic aspects from production to sale. In: Picq, C., Fouré, E., Frison, E. (Eds.), Bananas and food security. International Symposium, Douala, Cameroon, 10-14 November 1998, INIBAP, Montpellier, France : Pp. 39-58.

Rahman, M. M., Rabbani, M. D., Rahman, M. A. and Farid Uddin, M. D. (2002): In vitro shoot multiplication and rooting of Banana cv. Sabri. Pak. J. Biol. Sci. Vol. 5(2): Pp. 161-164. 